\title{
Management Analysis and Research of E-Government Platform Based on Community Development
}

\author{
YueJin Zhang ${ }^{1, \text { a }}$ SuLing Li ${ }^{1, b}$ HuiLi Zhang ${ }^{1, c}$ \\ ${ }^{1}$ Nanchang Institute of Technology, Nanchang, Jiangxi, 330044, China \\ aemail, bemail, ${ }^{\mathrm{c} e m a i l,}$
}

Keywords: Community Informatization, E-Government Platform Development, Construction

\begin{abstract}
According to the characteristics of the foreign community information development mode, combined with community informationization development in China, analyzes the problems existing in the development of information technology, the paper raised the mode of community development in our country in the future information industry chain and strategy. The human resources strategic planning scheme which conforms to the construction requirements of the community e-government platform does not represent the expected results. The quality of the results depends on the organization, system, culture, and the protection of education. Efficient and flexible organization is very important, but the community's political system is the fundamental guarantee of electronic government affairs platform construction of strategic human resource planning, the community also must form advanced excellent community culture to form a strong cohesion, in addition, the need of community platform of e-government platform construction of strategic human resource planning implementation also need education as a guarantee.
\end{abstract}

\section{Current Situation and Problem Analysis of Urban Community Management}

Community e-government platform platform can be said to be the intersection of vertical and horizontal information, is the key link of block connection, but also the breakthrough point of China's e-government platform construction bottleneck problem. The e-government platform is built on Chinese is a powerful defense to prepare quarantine departments in accordance with the social needs of a unified e-government platform integration, construction and development of human resources is an important bottleneck restricting factors of China's e-government, city community management of human resources is not only very weak, and there is not enough pay attention to. The important reason is that the strategic thinking is incomplete and comprehensive, which makes the unity become sharp contradiction. In view of this, our country has not yet fully started the construction of high-quality urban community e-government platform, we must pay attention to the special importance of human resources strategic planning. However, the human resource planning scheme that conforms to the requirements of the community e-government platform does not represent the expected results, and the results depend on the specific implementation plan. The implementation of the plan requires the protection of many measures, especially the organization, system and culture.

The concept and definition of community informatization changes as a rapidly developing thing. There is no doubt that the basic purpose of community informatization is to enable community residents to effectively enjoy the convenience and benefits brought by information technology. So we can describe the community information through computer technology, various kinds of realistic community cultural resources and life service information is mapped to the community information system, therefore, community residents can achieve a full range of communication and social relationship, between the family and the family through the Internet and other information systems, households and businesses, households and government departments more closely, the use of social 
resources more convenient and effective, in order to meet the increasing information demand and service demand, thereby greatly improving the quality of life of the modern community residents. Most residents are also the most direct and easiest to feel the benefits of community informatization from the community information system, and enjoy the benefits of information technology. Community information system is directly related to the interests of the residents and the community system; government departments in the process of formulating and adjusting development plan, can provide the basis for decision-making; community information system data provides the basis for decision support and other information system, also realizes the social emergency response system.

Research and application of community information about starting in 1995 in developed countries, the research is divided into two levels: one is study from the perspective of the government, the research content of this part is mainly concentrated in the community information collection and dissemination and national security and other aspects of the specification; the other one is from the perspective of social groups. Personal and social components are closely related, mainly focused on the application of information technology in group work, especially in health, vocational training and continuing education in specific fields. Community information construction is an important part of foreign community information construction in recent years, and also an important part of e-government platform construction. Vigorously promoting community construction is the inevitable result of the economic and social development of the country and the city at a certain stage. It is also an important way to modernize the city in the new century. At the same time, the development of information technology has provided unprecedented opportunities for the development of community construction. Promoting community construction through informatization is an effective way to achieve the goal of community construction. In the development of community information management and service system in foreign advanced cities, with its own characteristics, development goals and corresponding promotion plan, and began to build comprehensive testing of digital communities, important progress has been made.

Similar research abroad will focus more on the "constituency" information technology and e-government platform $\mathrm{G}$ to $\mathrm{C}$ level, more emphasis on the impact of information technology on the lives of residents. The European Union has established the "digital Europe (European) action plan", with particular emphasis on the establishment of community technology centers and Internet public access points, as well as free training. The British government also with organizations or non-governmental organizations, to carry out various promotional activities to raise public awareness of the Internet, and provide free services for the elderly, the disabled, low income, unemployment and other vulnerable groups. The United States established a community technology center in the city and countryside, and the use of community technology centers, public libraries and other public institutions to provide Internet access services for the Public Service Commission; the office of management and budget, the Ministry of education, museums and libraries also jointly developed online guide, and distributed to the community center, public libraries and other public technology institutions, how to explain to the public through the Internet to access information and services, and provide online resource guide.

Although the development of community informatization in China started late, it has developed rapidly in recent years, and the tide of community information construction has been springing up all over the world. Whether horizontal comparison or vertical comparison, the whole region has shown the characteristics of various forms of practical effect and coexistence. The development can be divided into three levels: the first level is the community service network based on telephone network, community service center hotline opened, to the residents informed that residents can seek 
help from the community service center through community service hotline; and the introduction of the computer second levels of telephone network based on the residents to the community service center can find information, seek help however, because the computer is not connected to the Internet, a small amount of information, update speed is slow, therefore, the community service is not a country fundamentally change and other services; the third level is the computer network in the community service, compared with the previous two forms, with more services, has the characteristics of extensive and convenient network characteristics of residents the. Beijing, Shanghai and Guangdong are leading in this respect.

Through the analysis of the current situation of community informatization in China, it can be seen that the construction and application of community informatization in China will show the main trend in the future:

First, promote public services to the information technology community, so that public services closer to the public. To emphasize the quality of information services for the community residents, a clear responsibility from the community management policy of the authority and status of informatization construction, standardize community public service organizations, the establishment of data acquisition and access system, disorderly extension improve the community public service. To this end, according to the requirements of community information, we should fundamentally straighten out the relationship between the strip and block, to facilitate the starting point, the merger of similar management functions and similar management institutions.

Two is to promote the community community service institutions informatization construction, and effectively realize the community residents information technology services. In order to improve the efficiency of community management, improve the ability of community service as the starting point, the scope of work to establish a network of basic community committee in strengthening community neighborhood committee office automation level, improve the transparency of community autonomy, and promote the standardization of community service for standardization, process. In order to meet the needs of people's life and culture, it is necessary to strengthen information training, improve the awareness of information, and truly realize the information technology services of community residents.

Three is to strengthen the construction of grassroots democratic information channels, and promote community residents democratic decision-making, community affairs. The development of democracy at the grassroots level and the construction of grass-roots organizations of the party promote the construction of other grass-roots organizations, and information technology can play an important role. The various channels of information construction as the key point, executive supervision and management responsibilities, the community autonomous organization of community, community talk about love "as the main content, the establishment of public communication platform, the establishment of residents' interest expression and coordination mechanism, promote the self contradictory problems in the community, and promote the management of effective self management and social management, including attracting young workers and retired residents to participate actively, strengthen community self-management, self-service and self-education ability, realize the government administration and the grassroots autonomous effective cohesion and benign interaction. Community informatization construction and operation is a complex system engineering, involving business process reengineering, management and supervision system, standards and other aspects of the content, is a comprehensive work. In the seventeen Party Congress report, put forward the "urban and rural construction, the construction of orderly management, perfect service, civilized and harmonious social life community" construction goal, is an effective way to realize the whole society to build a 
harmonious society

\section{The Management of E-Government Platform in the Future Community Information Development Mode}

Information technology as one of the national development strategy, to reflect the status of communication technology and the level of economic development to a great extent; an important part of community informatization and e-government platform, will inevitably reflect the e-government platform for government and civil service maturity. From this point of view, the government is also the absolute dominant of community informatization. However, through the above analysis, with the construction of community information further mature, to further expand the scale and service functions, to further improve the construction of large-scale investment, service bigger, it will far far beyond the streets and other function, need a large number of enterprises and social organizations to participate in the construction and service. At the same time, community informatization is a market to be developed, which is not only an opportunity for enterprises, but also a challenge for enterprises

The profit point of market and the attraction of enterprise investment will promote the development of community informatization to a great extent. In addition, community information services include small services such as housekeeping, maintenance, family education and so on. Individual operators will also become an important provider of community information services. Here, the information industry chain of this community is mainly composed of five parts: leadership, investment subject, main body construction, user and service. The following suggestions are put forward for the construction of future community informatization strategy:

(1) Government investment and enterprise combination. Community informatization is not only the behavior of the government, but also an important measure to meet the needs of citizens and improve the quality of life of the people. At the same time, it also opens up a new market for enterprises. The government should introduce enterprise investment, encourage enterprises to actively participate in appropriate projects, and give policy support. This will not only reduce the burden on the government, but also expand the community informatization construction team, creating opportunities for the development of enterprises.

(2) Provide free education. As we all know, provide some solid service of community information service mainly through web services, service hotline and service network; easy to use, the largest amount of information, through the website to find the required information service is the future trend of the development of community informatization

\section{Coping Strategies of Urban Community Management in E-Government Environment}

With the advent of the information age, e-government has entered the general trend of society. Therefore, the community management must make corresponding adjustment, take the correct coping strategies, the electronic government can better serve the community.

1. organization structure of work flattening. The traditional organizational structure of the community government is a rigid and rigid organizational structure with fixed position and strict hierarchical relationship. The excessive management level will affect the speed of information transmission, increase the communication and coordination costs between administrative personnel and grass-roots units, and increase the complexity of management work. E-government, such a large amount of information flow on the Internet sharing, not because of the information transmission channel, reduce the distortion of information, openness, sharing, and loyalty to the 
information asymmetry, not only can obtain a high level of global information in a timely manner, and in the different level of employees can also obtain global information so that an intermediate level of community management agencies and their staff will gradually lose the reason and basis of it, it can greatly reduce intermediate links, reduce the cost of human resources management of the community organizations, expand the management it can promote the transformation of the organizational structure from traditional bureaucracy to the plane of the network, so as to improve the performance of community management.

2. professional managers. Lack of managerial talent has become a hindrance. The bottleneck of the development of modern society is that many community workers are neither professional nor professional, and more part-time workers. Even if there are a few professionals, but also because of low wages, wages and occupation change, community management and learning electronic government talent is relatively small. Therefore, in order to make e-government serve the community better, we must employ and train professional community management talents. Through selection and employment, the structure of community management personnel can be optimized. Can be carried out in the form of open recruitment, through qualification examination, assessment, assessment and other aspects of the preferred selection. At the same time, we should pay attention to training, enrich the knowledge of information and e-government, and improve the overall quality of community management personnel. The method of combining vocational training, knowledge updating training and practical skill training in Haishu District of Ningbo city is adopted. Changsha Yuelu District has made great contributions to the training of community management talents in Colleges and universities.

In a word, the development of urban community and social progress is closely related to economic development. Doing well the management of urban community is not only beneficial to promote the deepening of urban reform, but also to the political participation and social stability of urban residents. In this era of high-speed information, we must conform to the trend of the times, let the electronic government into the community, into community management, formulate appropriate coping strategies. Only in this way can China's urban communities develop healthily and steadily so that community residents can enjoy the happiness and convenience brought by the information age.

\section{Acknowledgements}

Fund project: this thesis is the 2015 jiangxi province education department science and technology research project, project number: GJJ151179, name of the project: the community developing e-government platform management technology research, periodic series of research results

\section{References}

[1] on community e-government platform construction [J]. Huang Li, Shen PU. 2009 (17) of contemporary economy.

[2] community platform of e-government information behavior research in Qiaokou District of Wuhan city yijindun street community as an example [J]. Liu Jing. Hubei Social Sciences, 2009 (11).

[3] of city community management [J]. Wang Dong, e-government platform under the environment of Hou Xiufang, Chen Xiangchun. Journal of Hebei University of Economics and Business (Comprehensive Edition) 2007 (02).

The peripheral nerve of [4] e-government platform: community informatization [J]. Wu Tian. 
Information construction. 2007 (09)

[5] e-government platform and community informatization [J]. Du chain. Chinese urban economy. $2006(01)$

[6] design of community e-government platform system based on Struts framework [J]. Qu Zhaoyang, Wang Hongyu. Journal of Northeast Dianli University. 2006 (01)

[7] Gu Qin, Liu Jie, Peng Zongzheng. Research on government informatization of urban street community [J]. Computer engineering and design, 2004, (12)

[8] Cai Lihui. E-government: Reinventing Government in the information age [M]. Beijing: Chinese Social Sciences Press, 2016.

[9] Xu Xiaobo. Bureaucracy under the background of e-government [J]. Journal of Wuhan University of Science and Engineering, 2016, (11)

邮寄地址 江西省南昌市昌北经济开发区南昌理工学院英雄校区白老师收 13479126199 邮编 330044 